\title{
Kindergarten Teachers and Moral Education for Young Children: Why Do Narratives Matter?
}

\author{
Maila Dinia Husni Rahiema ${ }^{\text {a }}$ Nur Surayyah Madhubala Abdullah ${ }^{\text {b }}$, Steven Eric Krauss ${ }^{c}$ \\ ${ }^{a}$ Universitas Islam Negeri (UIN) Syarif Hidayatullah \& Universiti Putra Malaysia (UPM) \\ bUniversiti Putra Malaysia (UPM) \\ 'Universiti Putra Malaysia (UPM)
}

Corresponding e-mail: mailadinia@uinjkt.ac.id

\begin{abstract}
This paper reports a study on kindergarten teachers' use of narratives in the teaching and learning of moral education. The study posed the question: why do kindergarten teachers use narratives in teaching and learning moral education for young children? The study took place in two kindergartens in Indonesia, one an Islamic kindergarten located on the outskirts of Jakarta, and the second kindergarten a public kindergarten, non-faith based, located in South Jakarta. A total of 14 teachers were selected based on purposive sampling. Participants were selected for their sensitivity, knowledge, and insight into their experience. The kindergartens were selected due to their use of storytelling in learning. Primary data collection was through semi-structured in-depth interviews and focus-group discussion. Supplementary data were collected using observation and document analysis. Themes were obtained from coding and categorizing interview transcripts and analysis of documents. Findings revealed three reasons that teachers use narratives in teaching and learning: they believe narrative inspires children to behave prosaically; they believe that narratives motivate children to have good character; and they believe narratives are able to strengthen children's faith in God. The study concluded teachers play an important role in the success of moral education in schools and the quality of moral education through the use of narrative can be improved by improving ways of teachers' understand moral education and the objectives of moral education in the curriculum.
\end{abstract}

Keywords: $\quad$ Narratives, Moral Education, Young Children

\section{INTRODUCTION}

Narrative is a story that is told or written (Merriam-Webster Dictionary, 2016). The narrative is a description of factual or fictional events, acts, situations, and characters, using the technique of telling or narrating (ibid). Narratives are an effective medium of communication and to convey messages containing moral values (Gooderham, 1997) Through narratives, advice can be delivered in a fun way, that is easily understood by children (Nusbaum, 1978). The use of narratives for moral education has a long history and is universal (Tappan \& Brown, 1989). Many have said that narratives are central to the study as well as the teaching of morality (ibid). Lickona (1991) explained how the method of using narratives for moral education has been used for years because stories do not impose people to do but attract people to do. The use of imagination in the stories touches people's hearts (McGinn, 1997).

In Indonesia, narratives have been used for a long time for many purposes. Narratives are a part of the tradition, culture and identity of the Indonesian people (Murti Bunanta, 2003). Each ethnic group in Indonesia has its own narratives. Narratives have been used for one generation to another, to teach religion, tradition, history, and moral. Each ethnic group also has unique ways of narrating stories. They present stories in creative ways. They read, dramatize, sing, and dance. It is entertaining and enriching (ibid). 
In recent years, the use of narratives as instructional media is coming back as a trend in early childhood educational institutions in Indonesia. The government actively makes narrative more familiar through their publication and also training. Workshops on the methods and materials of narrative as intructional media are held and organized by the Ministry of Education. Narrative is now a daily activity that is used for teaching language, entertaining children and has also been widely used by many teachers for teaching values to young children. Even, the idea of using narrative for Moral Education is becoming a 'trend'. For years, the most commonly practiced moral education program in many kindergartens in Indonesia is applying habituation model for behavioral formation model. The scope of the kindergarten curriculum in Indonesia includes the following aspects of development: moral and religious values, social, emotional, and self-reliance, language skills, cognitive skills, physical / motoric skills, and art skills. The six developmental aspects are integrated into two integrated programs, which are: The formation of behavioral development using habituation on aspects of moral and religious values, social, emotional and self-reliance and the development of basic skills on aspects of language skills, cognitive skills, physical skills, and art skills. Moral education is part of the behavior formation through a habituation integrated program. The habituation model is facilitating the child to understand the various issues related to daily life, both at school and in the wider environment (family, friends, and community). This kind of model has a goal to make students aware of the good behavior, encourage them to behave right, and then make the behavior as a habit. The program prepares students to establish as early as possible attitudes and behavior based on the values in religion and society

The previous research and theories explained that the use of narratives is compelling for moral education, the government has socialized the methods through seminars and workshops, and then a lot of schools have already implemented the use of narratives for moral education, yet how do the teachers perceive this method? Why do they use narrative in teaching and learning moral education for young children? This paper is expected to provide information on the reasons of teachers in using narrative in teaching and learning moral education in kindergarten. If narratives are effective for moral education for young children, how do teachers understand and see it? An understanding from the teacher's perspective will help us to see how effective is the actual use of narratives as an alternative model of teaching and learning moral education in the kindergarten to meet the challenges of the curriculum.

\section{LITERATURE REVIEW}

In almost every culture in the world, we can find stories and the tradition of telling stories. Narratives have been used to introduce and explain many great ideas and concepts, including morality. A narrative is also one of the ways that have been used by many people to influence others. During the election campaign, candidates use stories to influence others. They share their success story, how someone who was born in an underprivileged family and now is a wealthy merchant; this person wanted to be a leader and need people to vote for him. Hochstetler (2006) agreed narratives play a significant role in our lives. We can learn many things from a story about the history, values, and beliefs, ideas, good and evil. Stories can be used to convince people, strengthen the moral standards of the society. The story gives examples of life, such as about honesty, integrity, and lots more.

Many have said that narratives are central to the study as well as the teaching of morality (Tappan \& Brown, 1989). Lickona (1991) explained how the method of using narratives for moral education has been used for years because stories do not impose people to do but attract people to do. Imagination in the stories touches people's heart. Narratives do not only illustrate a general moral theory, but also display the complexity of morality. Narratives do not only depict solutions, but also aid the re-creation of moral perplexities. Narratives have ethical values, which consist of exemplarity and moral imperatives, and also, allow for better understanding of moral acts (Putnam, 1978). Narratives are a source of learning, the narratives allow us to understand love and goodness. Narratives explore the gap between goodness and our living. (Nusbaum, 1978)

Young children love stories. Stories teach them many concepts about life. There are many scholars who have examined how children study morality from narratives. Kilpatrick, Wolfe, \& Wolfe (1994) argued that the characters in a story help children to understand problems in different perspectives; to encourage children to share; and build a sense of empathy. Storytelling is a perfect way to teach children to think critically, realistically, but also imaginatively. Children learn from the stories of how people solve their problems, make friends, or helping others. 
Bennet (1995) argued that heroic stories will inspire kids to do good things. DeVries \& Zan (1994) thought stories could be an effective medium to discuss the moral dilemmas and the discussion could empower children to develop their rational capacity. Stories discuss situations and events that maybe the readers have never experienced before, problems they may never have had. They learn from the obstacles faced by the character in the stories, how they face it and find solutions. They learn the consequences of doing certain things and rewards for doing good things. Anderson \& Groft (1972) believed that children can learn from stories because stories provide experience. Stories are a portrayal of life and mind in the form of words. Stories influence the way children think and behave. Children like to hear or read stories over and over again and it makes them remember details in the stories. This repetition with the combination of the children' imagination makes stories one of the best ways to influence thinking.

Krogh \& Lamme (1985) explained that narratives are useful for moral education, and combining children's literature with a lively classroom discussion about moral issues in the story will promote children's moral development. Stories offer a resource for moral education whereby children can learn through the 'experience' of those in the story (Winston, 1998). Junker (1998) conducted interpretive research on how children explored moral issues when they participated in literature groups. Junker found out that they are interested and aware of moral concepts. Children are engaged in moral talk. They commented on moral events or stances in the text, they interpret the text, they shared other stories in response to the text, and they discuss moral issues.

Using narratives for moral education is beyond teaching right and wrong. Winston (1998) explained moral education is a process whereby children learn to develop their understanding of good and evil, to think about their action affect others, to express values as caring, respect and responsibility. A narrative is a useful tool for moral education, to introduce the concepts of fairness, human rights, and human welfare.

The use of narratives for moral education allows children to look at situations from another perspective. They are exposed to different worlds. By using stories children process information, and better remember it. Stories make the situation real and invoke emotion. Stories help people better learn and retain information. Children get to see solutions and alternatives because stories are less abstract and provide the opportunity to look at problems from other viewpoints. (Butcher, 2006).

\section{METHODOLOGY}

The method of inquiry for this research is qualitative research. A criterion-based and purposive sampling strategy was employed to choose kindergarten teachers who have experience and practice in using narratives for moral education. Participants were selected for their sensitivity, knowledge, and insight into their experience. Although the decision to participate was strictly voluntary, the participants who did choose to participate in this study appeared to fit the role defined by those criteria, in that they were well established in early childhood teaching and, therefore, privy to the nature of the interview questions posed by the researcher. The criteria made by the researcher are the teachers have been teaching for more than two years, and they use narrative in their classes.

The study took place in two kindergartens, one is an Islamic kindergarten, we use pseudonym name Jasmine Kindergarten, located on the outskirts of Jakarta. An Islamic kindergarten is a faith-based kindergarten, where pupils are children of same religion. The second kindergarten is Rose Kindergarten (pseudonym name), a public kindergarten, non-faith based, which is located in South Jakarta. Both kindergartens have a good reputation within the community as creative and innovative kindergartens. They have consistently and regularly incorporated narratives into the students' curriculum while the teachers use the method of narrating stories in learning. Both kindergartens were chosen on the advice of the key respondents of the research, whom happen to teach a weekly science program at both schools.

To get richer and deeper insight into the phenomenon of study, we used multiple research methods to study the phenomenon. We conducted indepth interviews, observed storytelling practice and bookstore visits, and examined the list of books owned by the school and school documents. The purpose was to strengthen the findings obtained from the research through triangulation. Triangulation is used to bring different sources of information to confirm one interpretation and make the argument more convincing and credible.

The initial subject of this research is a retired teacher, who has 25 years' experience as a kindergarten teacher, and now she is working as a storyteller for paid and social performances. She recommended the researchers to interview 7 teachers from Rose Kindergarten, a general, non-faith based kindergarten; 4 teachers from Jasmine Kindergarten, an Islamic Kindergarten; and two art-science teachers 
who teach in both schools. Both kindergartens have been chosen as research sites because they have an excellent reputation within the community as creative and innovative kindergartens. They have consistently and regularly incorporated storytelling activities into the students' curriculum while the teachers use the method of storytelling in learning. The teachers in both schools have experience in using narratives as teaching tools. Each participant interviewed 3-5 times for approximately 30-120 minutes. Interviews were tape-recorded and then transcribed to categorize information into a coding scheme. Focus Group Discussion with the teachers was held one time in each school. Researchers observed one visit to bookstore. Documents collected are: National Curriculum, the kindergartens' school program, introduction booklet, information on the internet regarding the two kindergartens, lists of books owned by the school, titles of selected books by teachers and the most favorite books for children, and copies of each of those books. Total time spent in the field is 8 months.

Data analysis occurs simultaneously and iterative with data collection, data interpretation and report writing. Data analysis is based on the on data reduction and interpretation - decontextualization and recontextualization. In this research, data analysis began with identifying the themes emerged from the raw data. Corbin and Strauss (2007) refer this process as "open coding". The next stage of analysis, we re-examined the categories identified to see the connection. This complex process sometimes called "axial coding" (ibid). Finally, we translated the conceptual model into the story line that will be read by others. The purpose was to ensure that the research was a rich, tightly woven account providing an accurate picture of the reality studied.

\section{FINDINGS}

The findings revealed there are three reasons the teachers have for using narratives in teaching and learning moral education in kindergarten, the first reason is because they believe narrative is inspiring children to behave prosaically. The second one is, they believe that narratives motivates children to have good character. And the last reason is they believe narrative are able to strengthen children's faith in God.

Inspiring children to behave prosocially became one of the reasons of kindergarten teachers using narrative for moral education. The teachers do not use the word prosocial behavior in their explanation, but they give examples of behavior, which are categorized as prosocial, among others: to care, empathize, to work in a team, to love their family, to obey their parents, to protect the environment, to put others as consideration of action, to care for animals, and to love and care for others.
I use stories most of the time as a way of teaching a lot of things including moral values. When there is an event, incident, umm... or a child did bad things or hurt others, I would not just tell the story right away, umm... but I will wait for a good moment to tell the story. Story inspires children to do well, umm... to care, to empathize and many others.

The arguments of teachers that narrative could inspire students to behave prosocially is similar to what Noddings (2002) explained that stories can inspire children about how to interact with others in real life. They learn that people are different and need to respect them. The teachers stated that using narratives is more effective in teaching children to behave well or to behave prosaically, rather than just giving instruction what to do. This suggests similar to Kilpatrick, Wolfe, \& Wolfe (1994) who argued that the characters in a story help children to understand problems in different perspectives; to encourage children to share, and build a sense of empathy. They added storytelling is a particularly good way to teach children realistic thinking as children can see in the stories how people solve their problems. Nobes and Pawson (2003) stated that children can learn and understand social rules and authority from a storybook. They learn how characters in the story fail to follow the rules and what the consequences are for them and the others.

The findings of this research illustrate that the reasons teachers use narratives for teaching and learning moral education for young children, because narratives are able to inspire children to have a good character. Cendana explained one of the ways of teaching good character is through narratives. She gave an example of how narratives could teach children to be responsible:

...Umm then I tell the story of the family, for example, each member of the family has responsibilities, there is a mother whose job is what, umm... dad his job is what, but there is one child, he actually has the duty and responsibility, but he does not do his job. 
This teachers's reasons of using narrative for moral education is similar to the definition of morality as explained by virtue ethics theory. The Virtue Ethics Theory argues that the moral value of actions depends on the extent to which they exhibit certain traits of the person. Pertaining Virtue Ethics Theory as the foundation of moral education means just promoting virtues in the classroom. The aims of Moral Education here mainly concerns with the promotion of desirable or admirable character traits. Carr \& Steutel (2005) stated that to regard virtue ethics as the theoretical base for a conception of moral education would presumably be to envisage moral education as a matter of the development of traits, along with the promotion of some understanding of moral value and significance.

The teachers from Islamic kindergarten of Jasmine related the character with the noble character as such exemplified by the prophets and told in the Qur'an, as such honesty, gratitude and integrity. They stated the Prophet Muhammad is considered the perfect moral exemplar.

I often take the story from the magazine, it is actually a (children) science magazine, but there are also stories of the Prophets. We teach children stories of the Prophets, umm... so they follow the behavior of the Prophets.

This study reveals that one of the reasons teachers use narratives for teaching and learning moral education for young children is because they assured that narratives could strengthen children's belief in God and to worship the God. This suggests similar to Aitken's (2001) research on storytelling and Christian conversion in children. She said Children between 2 and 7 love to learn new things. This is an excellent time to provide them with great stories. They can learn about nature, relationships, and God from the stories. Aitken also added this is also a good time for children to get to know the characters in the bible.

They said narratives help explain about the importance of praying and the greatness of God through stories. The teachers who explained this reason are the three key respondents and all the teachers from Jasmine Kindergarten. They explained that the narrative strengthens children's faith, they will believe more in religion, they learn how great God and His creation are. They further explained that this faith will make them more grateful to God, to obey God, and to worship God.
So, if I tell stories to children, I have to instil religious values in children. So life is very close to God. If we talk about the creation of nature, especially in the early days, the tree, we know the tree was created by God. Now children know God? God who? Our Lord. Where is it? The heavens? Large or small? Big. We've never seen it? How do you know God is big? God is great. (Muttering) The world is also great. Children look to the big sky. God, who created it was definitely bigger. To practice, so that students understand, let children make anything, something. What kids will make of plasticine. Try to make a puppet, can you make the puppet move? But if God created it, certainly the puppets could move. So, if we tell a story, the story will surely end with religion.

\section{CONCLUSION}

In conclusion, the teachers use narratives for moral education are because narratives are effective in inspiring children to behave prosaically; to motivate children to have good characters; and to strengthen children's faith in God. From the researchers' observation, the teachers use narratives for moral education, but they use it as no different from giving instructions. The many good aspects of stories for moral education are not exercised. The researcher suggested that the teachers should give an opportunity to children to make their own meaning in the story, to make storytelling different from preaching or giving instruction. Barrow (2007) explained that moral education is different from moral training, moral conditioning, or moral indoctrination. By telling stories teachers engage with children in moral thinking and enrich their understanding of moral thinking and feeling. McGinn (1997) explained how narratives allow students to be involved with the process of developing moral judgments. He stated the fictional work "can make people see and feel good and evil in a way that no philosophical tract can."

The teachers are aware that narrative has benefit for inspiring and motivating children. However, teachers should be well informed on how actually stories could be an effective media of moral development for children, and also, teachers should understand that moral education is different from moral training. 


\section{REFERENCES}

Anderson, W., \& Groft, P. (1972). A New Look at Children's Literature. Belmont, CA: Wadsworth Publishing Co., Inc.

Barrow, R. (2007). Introduction to Moral Philosophy and Moral Education. London: Routledge

Bennet, W. (1995). Books of Virtues. New York: Simon \& Schuster

Butcher, S.E. (2006). Narrative as A Teaching Strategy. The Journal of Correctional Education, 57 (3), 195-208

Carr, D. \& Steutel, J. (2005) 'Virtue Ethics and the Virtue Approach to Moral Education' in J. Steutel \& D. Carr, (Eds) Kids of Character: A Guide to Promoting Moral Development, NY: Routledge.

Cassidy, K. W., Chu, J. Y., \& Dahlsgaard, K. K. (1997). Preschoolers' ability to adopt justice and care orientations to moral dilemmas. Early Education \& Development, 8, 419

Corbin, J., \& Strauss, A. (2007). Basic of Qualitative Research: Techniques and Procedures for Developing Grounder Theory 3rd Edition. New York: Sage Publication Inc.

DeVriez, R. \& Zan, B. (1994). Moral Classrooms, Moral Children: Creating a Constructivist Atmosphere in Early Education. New York: Teachers College Press

Dunn, J. (1990). The Beginnings of Moral Understanding: Development in the School Year. In J. Kagan \& S. Lamb (Eds). The Emergence of Morality in Young Children. Chicago: The University of Chicago Press.

Gooderham, D.W. (1997). What Rough Beast...? Narrative Relationships and Moral Education. Journal of Moral Education, 26:1, 59-72.

Hochstetler (2006), "Using Narratives to Enhance Moral Education in Sport", Journal of Physical Education, Recreation \& Dance, vol 77, issue 4, pages 37-44.

Junker, M. S. (1998). Searching for the moral: Moral talk in children's literature study groups. Doctoral dissertation, Arizona State University, 1998.

Kilpatrick, W., Wolfe, G., \& Wolfe, S.M. (1994). Books that Build Character: A Guide to Teaching Your Child Moral Values. New York: Touchstone

Krogh, S. L., \& Lamme, L. L. (1985). Children's literature and Moral Education. Young Children, 40, 48-51.
Lamb, S. (1993). First Moral Sense: An Examination of the Appearance of Morally Related Behavior in Second Year of Life. Journal of Moral Education, 22:2, 97-109.

Lickona, (Ed), 1991, Moral Development and Behavior. New York: Holt, Rinehart \& Wilson.

McGinn, C. (1997). Ethics, Evil and Fiction (1997). Oxford University Press.

Murti Bunanta (2003). Indonesian Folktales (World Folklore). Libraries Unlimited.

Nobes, G., \& Pawson, C. (2003). Children's Understanding of Social Rules and Social Status. Merryl-Palmer Quarterly: 49: 1, 77-99

Noddings, N. (2002). Starting from Home: Caring \& Social Policy. Los Angeles: University of California Press

Nussbaum, Martha C. (1986). The Fragility of Goodness, Luck and Ethics in Greek Tragedy and Philosophy. Cambridge: Cambridge Univeristy Press.

Tappan, M.B., \& Brown, L.M., (1989). Toward A Narrative Approach to Moral Development and Moral Education. Cambridge,MA: Harvard Educational Review

Vandenplass-Holper, C. (1990). Children's Books and Films as Media for Moral Educations: Some Cognitive-Developmentally Oriented Considerations. School Psychology International, 11: 31-38.

Winston, J. (1998). Drama, Narrative and Moral Education: Exploring Traditional Tales in the Primary Years. Psychology Press.

Wringe, C. (2006). Moral Education: Beyond the Teaching of Right and Wrong. Springer. 